This item was submitted to Loughborough's Research Repository by the author.

Items in Figshare are protected by copyright, with all rights reserved, unless otherwise indicated.

\title{
Safety implications of co-locating road signs: a driving simulator investigation
}

PLEASE CITE THE PUBLISHED VERSION

https://doi.org/10.1016/j.trf.2017.04.007

PUBLISHER

(c) Elsevier

VERSION

AM (Accepted Manuscript)

\section{PUBLISHER STATEMENT}

This work is made available according to the conditions of the Creative Commons Attribution-NonCommercialNoDerivatives 4.0 International (CC BY-NC-ND 4.0) licence. Full details of this licence are available at: https://creativecommons.org/licenses/by-nc-nd/4.0/

\section{LICENCE}

CC BY-NC-ND 4.0

\section{REPOSITORY RECORD}

Filtness, Ashleigh, Gregoire S. Larue, Amy Schramm, Joshua Fuller, Andry Rakotonirainy, Clarissa Han, and Peter Cairney. 2019. "Safety Implications of Co-locating Road Signs: A Driving Simulator Investigation". figshare. https://hdl.handle.net/2134/25108. 


\title{
Safety implications of co-locating road signs: a driving simulator investigation
}

\author{
Filtness, A.J. ${ }^{a^{*}}$, Larue, G. ${ }^{a}$, Schramm. A. ${ }^{a}$, Fuller. J. ${ }^{a}$, Rakotonirainy, A. ${ }^{a}$, Han, $C^{b}$. \& Cairney P. ${ }^{b}$ \\ a: Queensland University of Technology (QUT), Centre for Accident Research and Road \\ Safety - Queensland (CARRS-Q), 130 Victoria Park Road, Kelvin Grove, QLD, Australia \\ b: ARRB Group, 500 Burwood Highway, Vermont South, VIC, 3133, Australia
}

*Corresponding author: Ashleigh Filtness, Ph.D.

Present address: Loughborough Design School, Loughborough University, Leicestershire, LE11 3TU, UK

Tel: +44 1509226934

Email: A.J.Filtness@lboro.ac.uk 


\begin{abstract}
Background: As road complexity increases the requirement for number of road signs also increases, although the amount of road side space does not. One practical strategy to address this is to present multiple road signs on the same gantry (sign co-location). However, there is very little research on the safety implications of this practice.

Method: 36 participants (mean age $=42.25$ years, $S D=13.99,18$ females) completed three driving simulator scenarios, each scenario had a different sign co-location condition: no colocation, dual co-location and triple co-location. Each scenario presented similar information using direction signs, variable message signs and variable speed limit signs, under. Each drive included standard motorway driving $(100 \mathrm{~km} / \mathrm{h}$ speed zone) in free flow traffic and one emergency event where a lead vehicle suddenly braked. The scenario order was counterbalanced and the emergency event vehicle varied.
\end{abstract}

Results: Overall, there was no impact of co-locating signs on general driving performance. No significant difference was observed between conditions for reaction time and minimum headway in response to the emergency event. Participants were able to correctly choose their destination whether the signs were co-located or not.

Discussion: For the particular configuration of signs tested there is no evidence that colocation negatively impacts driving performance. However, there may be some implications for travel speed and the manner in which the emergency event is responded to. Future work should confirm the findings on real roads. These findings provided support for sign colocation as a practical and safe option for displaying multiple road signs in a confined area.

Key words: road sign, driving simulator, direction sign, variable message sign, variable speed limit sign. 


\section{Introduction}

Driving is a complex task, relying on psychomotor and cognitive processes in order to correctly monitor and understand the road, in order to make and execute appropriate safe driving choices (Dutta, Fisher \& Noyce, 2004; Ma \& Kaber, 2005). Road signs are an important part of the road environment, and are designed to help drivers reach their destination efficiently and safely (Möri \& Abdel-Halim, 1981; Siogkas \& Dermatas, 2006). They do this by providing navigational information, highlighting potential dangers and communicating current traffic conditions (Costa et al., 2014; Fang, Chen \& Fuh, 2003). In conjunction with the increasing complexity of our road systems, there is an increasing amount of information that needs to be conveyed to drivers, often in a dynamic way. Therefore there is a need for well-designed road signs to assist drivers (Mori \& Abdel-Halim, 1981). However, with limited road side space increasing signage may be difficult to accommodate. One potential solution to this problem is to make better use of the available space by presenting multiple road sign types on the same gantry or sign post, referred to here as co-location.

Road agencies are increasingly viewing co-locating road signs as a positive option, for example where multiple critical messages are required over a short distance of road, or budget constraints limit the number of new gantries that can be installed. Consequently, co-locating road signs has become common practice, particularly in the USA and Europe (Han et al., 2016). Conversely, some jurisdictions impose restrictions stating that different sign types may not be co-located, or they permit only dual co-location. Despite the prevalence of both sign co-location and regulations surrounding the practice, there has been very limited research into the safety implications of co-locating road signs. 
Recent developments in technology mean that electronic variable message signs (VMS) and variable speed limits (VSL) are becoming increasingly prevalent. Overall drivers have responded positively to VMS, recognising them as a useful medium for disseminating safety and travel information. (Chatterjee et al 2002; Chatterjee \& Mcdonald 2004). VSL are also a positive addition, allowing dynamic control of motorway speeds which improves traffic flow and reduces crash potential (Lee et al 2006). Furthermore, the effectiveness of VSL for reducing speed can be enhanced by supplementary VMS providing information about why the speed limit is being reduced (Lee \& Abdel-Aty 2008). In this case VMS and VSL were not co-located but presented independently. The most usual forms of co-location are pairing VMS with VSL or direction signs (DS) with VSL (Han et al., 2016).

The safety implications for co-locating road signs are unclear as the findings of the few investigations into this topic are varied. A recent simulator study using low density traffic conditions suggests potentially negative safety implications, as co-locating several sign types (DS, VMS, VSL) together increased glance duration towards the signs (Larue, Schramm, Smith, Lewis \& Rakotonirainy, 2013). Both dual and triple co-location of road sign types increased the mean glance duration towards signs to above the critical two seconds period. Naturalistic driving studies have shown that looking away from the road for a period of two seconds or more increases a driver's risk of crashes and near crashes (Klauer et al., 2006).

In contrast to these findings, an investigation into co-locating DS with advertising signs providing information about an approaching service station found no negative safety implications of co-location (Metz \& Krüger, 2014). In this series of driving simulator experiments, participants were asked to observe changes made to direction signs that were either not co-located or co-located with advertising signs. In one experiment this 
observation was made at the same time as responding to the sudden braking of a lead vehicle. Co-location had no effect on either the detection of changes to the direction signs or the response to the sudden braking event. The authors suggest that drivers are able to apply safe search strategies and direct their gaze to the information needed without being subject to distraction (Metz \& Krüger, 2014). However, it should be noted that participants of this study were not instructed to go to the service station and therefore the information in the advertising sign was irrelevant to them. It is unclear whether the findings would have been replicated if drivers were required to extract relevant information from the adverting and DS signs. Furthermore, the finding is in contrast to that of Edquist et al, (2009), who reported that irrelevant "visual clutter" slows a driver's ability to detect changes in photographs of road scenes.

Increasing the amount of information on road signs may make it harder for the driver to find the information they require. There are limitations to the amount of information humans can process, with evidence suggesting that only 3-4 items can be attended to simultaneously (Pylyshyn \& Storm, 1988; Trick \& Pylyshyn, 1994). The more information which is presented at one time, the harder it is likely to be for a driver to accurately process all of it. The location of any particular road sign is fixed, meaning that drivers have limited exposure to the presented information. From the point at which a sign becomes readable a driver has a set amount of time to perceive and understand the information they require. This time is influenced by travel speed. Additionally, the capacity a driver has to look at a road sign is influenced both by any manoeuvre they may be undertaking and by the surrounding traffic. By co-locating signs an increased volume of information is presented to a driver during the same period of time. As a result, this could mean that drivers are less 
attentive to the road and more likely to experience inattentional blindness (failure to detect an unexpected stimuli while performing a visual resource-consuming activity (Jensen, Yao, Street \& Simons, 2011)), which may impair their ability to respond to an emergency event. To evaluate this, the current work takes a uniformed approach to displaying road sign information relevant to driving, varying only the co-location status of signs and considering how driving performance is influenced. Best practice in terms of sign design e.g. font and colour, and co-location configuration is not evaluated, however it is acknowledged that these aspects may impact the ability of drivers to accurately extract and use relevant information (Schnell, Yekhshatyan \& Daiker, 2009).

A further negative safety implication posed by road signs is that they can be an external distractor. Distractions external to the vehicle are responsible for approximately $10 \%$ of all driving incidents (Young and Mahfoud as cited in Sisiopiku, Hester, Gan, Stavrinos \& Sullivan, 2013). To date, much of the available research on road signs as external distractors has focused on roadside advertising. Although the results of this research have been mixed, there is evidence to suggest that roadside advertising presents a small but significant risk to road safety (Edquist, Horberry, Hoskings \& Johnston, 2011; Lay, 2004). For example, visual distractions, such as advertisements, can impede driver performance by increasing the number and length of off-road glances (Kaber, Liang, Zhang, Rogers \& Gangakhedkar, 2012). Additionally, roadside distractors have also been shown to impair a driver's ability to detect and respond appropriately to hazards as well as their ability to stay within their designated driving lane (Divekar, Pradhan, Pollatsek \& Fisher, 2012). In this case the external distractor was a sign displaying a random collection of letters from which a target letter should be 
identified. It is not clear if similar results would have occurred if the distractor was relevant to the driving task.

Despite an increased potential for increasing driver distraction, very little empirical research has examined whether driving performance is maintained regardless of sign co-location. Considering that road signs are an integral part of road design (Castro \& Horberry, 2004) and that co-location is increasingly prevalent, the lack of research in this area should be addressed. The current driver simulator study takes a previous investigation a step further (Larue, Schramm, Smith, Lewis \& Rakotonirainy, 2013), by considering road sign co-location under higher traffic flow conditions and requiring the driver to react to an emergency situation. The following research questions are addressed: (1) Can drivers respond safely to an emergency event while extracting information from co-located signs, compared to conventionally located signs? (2) Does co-locating signs impact general motorway driving performance in terms of vehicle control and eye gaze? (3) Does co-locating signs increase subjective workload associated with driving?

\section{Method}

This experiment was undertaken as part of a wider study to consider the case for triple colocation of signs in a motorway environment (Han and Cairney 2015). It was important to determine whether drivers could extract the critical information from co-located signs when dealing with demanding driving tasks.

\subsection{Experimental design}

The study employed a repeated measures design using three sign presentation conditions: no co-location (conventionally located), dual co-location and triple co-location. All three conditions were experienced during the same testing session. The exposure order was 
counterbalanced, thereby removing the impact of any learning effects on the results due to repeated exposure to similar scenarios. During each scenario the road network and simulated traffic features remained consistent, with the exception of the co-location status of signs. All participants first completed a familiarisation drive to ensure that they were comfortable with the features and handling of the simulated vehicle. The study was approved by the Queensland University of Technology Human Ethics Committee.

\subsection{Advanced driving simulator}

The study was conducted using the CARRS-Q advanced driving simulator running OKTAL SCANer Studio v1.3 simulation software. Hardware comprised of a Bosch Rexroth E-Motion1500 Electric Motion System, which supplied motion with 6 degrees of freedom.

Additionally, six HP Z820 workstations, with GeForce GTX 680 2Gb graphic cards for the two computers with the higher load, and GeForce XFX 1GB graphic cards for the other computers, ran components of simulation software. Three Projection Design F32 (GP3) projectors, projected on three flat $4 \times 3$ screens at $1400 \times 1050$ resolution gave a forward view of approximately $180^{\circ}$ horizontal and $45^{\circ}$ vertical. Three 8 -inch LCD screens, with $800 \mathrm{x}$ 600 resolution replaced the central and side mirrors. A complete Holden VE Calais vehicle body with working controls and instruments was used. Eye movements were recorded using FaceLAB ${ }^{T M}$ software (Seeing Machines Ltd., Canberra, ACT) v5 from two infrared cameras installed on the vehicle dashboard.

\subsection{Driving Scenario}

Each driving scenario comprised an 8.35 kilometre motorway (three lanes of travel in each direction separated by a central barrier), which was adapted from an earlier road segment developed for Larue et al., (2013). Changes from the earlier study included an increase in traffic volume from 400 vehicles/hour/lane to 1300 vehicles/hour/lane, and the addition of 
an emergency event towards the end of each scenario. Additional visuals were kept to a minimum to reduce driver distraction. Three sign types were used: direction signs (DS), enhanced variable message signs (VMS) and variable speed limits/lane closure signs (VSL/LCS). Each type of sign was relevant to the driving task. A DS sign indicated the appropriate exit to take, the VMS indicated the relative proximity of the appropriate exit and the VSL/LCS indicated the speed limit and which lanes could be driven in. All signs complied with the requirements for colour, font, content and position as specified in the Queensland Manual of Uniform Traffic Control Devices (Transport and Main Roads, 2013) at the time of the study. However, the resolution and set up of the simulator projectors resulted in lower legibility for the simulated signs than would be the case for real signs. The size of the simulated road signs was therefore increased to achieve the same legibility distance as would be expected with real-life signs. The sign arrays used in the study are presented in Figures 1-3.
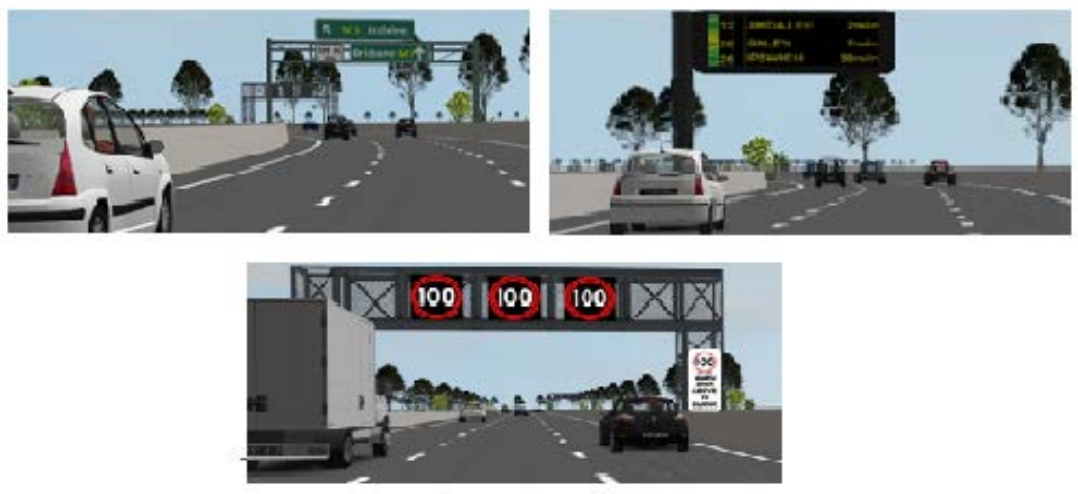

Figure 1. (Clockwise from left) Stand-alone directional sign, Stand-alone VMS sign, Standalone VSL/LCS. 


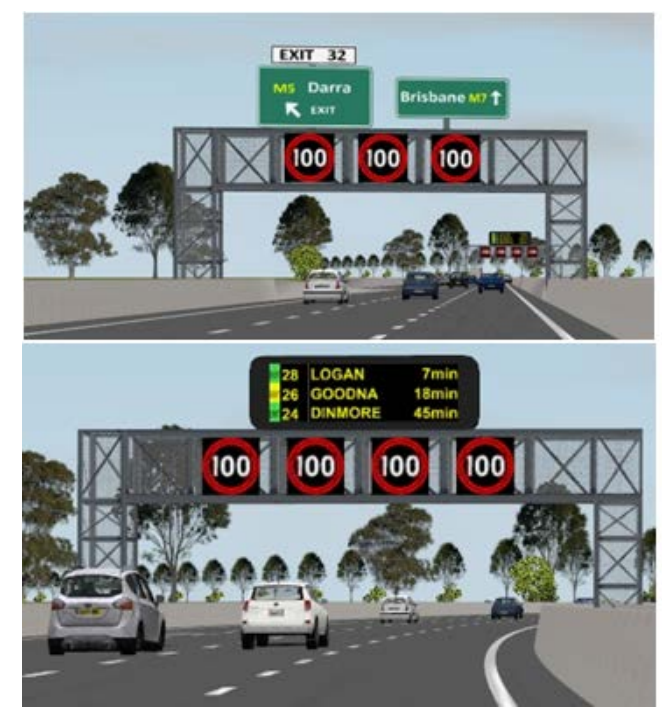

Figure 2. (Top to bottom) Dual co-location of directional signs and VSL/LCS; Dual co-location of VMS and VSL/LCS.

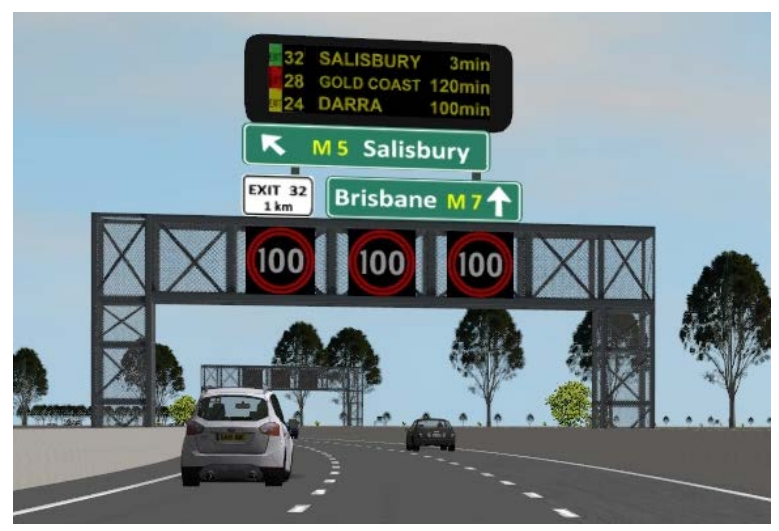

Figure 3. Triple co-location of VMS, directional signs and VSL/LCS.

The structure of each scenario is depicted in Table 1. Changes in speed and a lane closure occurred in every scenario and were indicted by the VSL/LCS sign. For each scenario, participants were instructed to drive to a different named destination. Trip distances were the same for all scenarios. An emergency event occurred near the end of each scenario, $500 \mathrm{~m}$ from the required exit, coinciding with a change in VSL information. Data was extracted and analysed for three zones of interest. Zone 1 comprised standard driving under free flow traffic (1300 vehicles/hour/lane) with a $100 \mathrm{~km} / \mathrm{h}$ posted speed limit, and measures were taken from $200 \mathrm{~m}$ prior to the second gantry to allow sufficient time for the 
participant to reach their desired travel speed. Zone 2 included the left lane closure within a $70 \mathrm{~km} / \mathrm{h}$ speed zone. Zone 3 comprised the emergency event under traffic conditions of 2600 vehicles/hour evenly distributed across 3 lanes. Measures were taken from 200m prior to the gantry under which the emergency event occurred until $150 \mathrm{~m}$ past the gantry. The current paper focuses on standard driving (Zone 1) measured during the first $100 \mathrm{~km} / \mathrm{h}$ speed zone and response to the emergency event (Zone 3). Zone 2 is not considered as free flow traffic conditions were not sufficiently maintained during the lane closure. This compromised the ability to evaluate the implications of sign co-location on driving performance in this zone.

Table 1. Structure of driving scenario

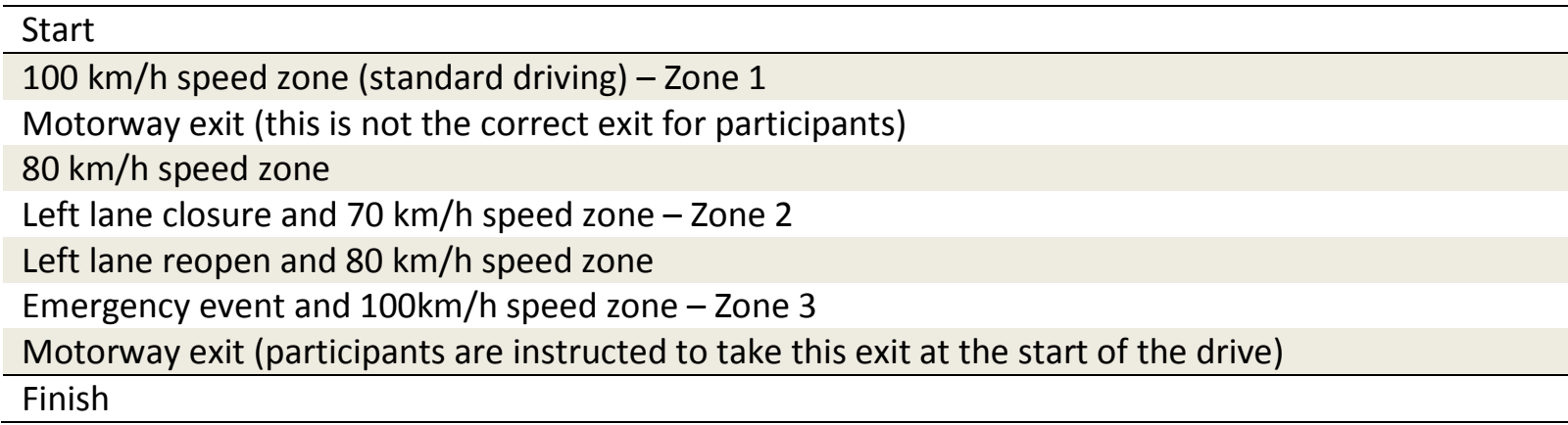

\subsubsection{Emergency event}

For the purpose of this study the emergency event was defined as: having a vehicle immediately in front of the participant's vehicle brake suddenly when approaching a sign. The sign in question indicated an increase in the speed limit from $80 \mathrm{~km} / \mathrm{h}$ to $100 \mathrm{~km} / \mathrm{h}$. The emergency event occurred once in each scenario. All emergency events occurred $60 \mathrm{~m}$ upstream from the change in speed limit sign, with the suddenly braking vehicle being 2 - 3 seconds headway ahead of the participant. To ensure a response from participants, the braking event vehicle was scripted to decelerate at $-5 \mathrm{~m} / \mathrm{s}^{-2}$ (approximately $0.5 \mathrm{~g}$ ). 
Steps were taken to ensure that the emergency event did not result in a collision in order to avoid influencing future driving behaviour. Firstly, the braking event vehicle was scripted to accelerate as soon as a collision was recorded; this would occur before a participant would notice a collision had occurred. In addition, the braking event vehicle was not scripted as a solid object, meaning that if participants did make contact with the lead vehicle, no realistic motion, audio or visual stimuli were presented to the participant that would suggest a collision had taken place.

\subsection{Participants}

A total of 36 participants aged between $21-69$ years (18 female; mean age of all participants 42.25 years; $S D=13.99$ ) completed the study. A further two participants were recruited but withdrew due to simulator sickness. All participants held a current provisional (first two years of driving) or open licence. Participant recruitment was stratified by three age groups ( $\leq 29$ years; $30-49$ years; $50+$ years), with 12 participants in each group. Upon the completion of the study, participants received $\$ 30$ to acknowledge their contribution.

\subsection{Dependent variables}

\subsubsection{Speed}

Speed related variables were recorded during Zone 1 at $20 \mathrm{~Hz}$. Data for the mean vehicle speed, maximum vehicle speed, and the standard deviation of mean speed $(\mathrm{km} / \mathrm{h})$ were collected. Additionally, the percentage of time the vehicle was above the speed limit was noted.

\subsubsection{Eye tracking}

Eye tracking data was used to measure the proportion of eye gaze time on the road and on the signs, as well as the mean and maximum duration of any one glance at a sign during Zone 1. 


\subsubsection{Emergency event response}

In Zone 3, in order to contextualise the conditions under which the emergency event took place, the participant's speed and headway (seconds) to the lead vehicle at the point the event started were recorded. Participants reacted to the emergency event using one or a combination of three responses: application of the brakes, release of the accelerator, changing lanes. Reaction time was taken to be the lowest observed value for any of the three types of response. For participants who did not change lane in response to the event, the minimum headway to the braking vehicle was recorded in time (sec).

\subsubsection{Decision making}

Participants were instructed to drive to a different location during each drive. The direction signs indicated which slip road should be taken to exit the highway. Motorway exit decisions were coded as correct or incorrect.

\subsubsection{Subject Workload}

Subjective workload was measured using a modified version of the NASA-Task Load Index (Hart \& Staveland, 1988). At the conclusion of each scenario participants were asked to rate how confusing, difficult, stressful, rushed, safe and successful the drive was on a 7 point scale.

\subsection{Data Analysis}

The analyses were conducted using IBM SPSS 21. Data were extracted for two key segments of interest: Zone 1; the free flow $100 \mathrm{~km} / \mathrm{h}$ speed zone at the start of each scenario, and Zone 3; the set location of the emergency event in each scenario. The speed related variables were analysed using a repeated measures ANOVA with the within-subjects independent variable of scenario (3 levels: no co-location, dual co-location and triple colocation). Post-hoc pairwise comparisons were performed using Bonferroni tests. Greenhouse-Geisser was used to correct for sphericity, with epsilon values listed 
accordingly. Post-hoc pairwise comparisons were performed where significant ANOVA results were found. The same ANOVA analysis approach was undertaken for results of the NASA-Task Load Index. A Linear Mixed Model approach was taken to analyse data from the response to the emergency event and eye tracking measures, using the independent variable of scenario, following Haque and Washington (2013). This approach was taken in order to minimise lost data due to unequal sample sizes between scenarios which resulted from failed measures in individual scenarios. Beta coefficients and confidence intervals are reported for results with significant main effects, using the no co-location condition as the reference group.

With respect to eye gaze behaviour, participants with poor tracking (difficulties with calibration, less than $85 \%$ successful tracking and/or no percentage gaze time spent looking at signs) were excluded.

\section{Results}

\subsection{Standard Driving $(100 \mathrm{~km} / \mathrm{h}$, no emergency event)}

\subsubsection{Vehicle dynamics}

Due to a technical failure, the driving simulator failed to record data for one participant; results are therefore presented for 35 participants. There was a statistically significant effect of sign co-location on maximum speed $\left[\mathrm{F}_{(1.70,57.93)}=7.905, \mathrm{p}=.002, \varepsilon=.85\right]$. Pairwise comparison identified dual co-location to be associated with a significantly slower maximum speed compared to no co-location $(p<.001)$. Dual co-location was also associated with a significantly slower maximum speed than triple co-location $(p=0.05)$. There was a also a significant main effect of sign condition on standard deviation of speed $\left[F_{(2,68)}=6.073, p\right.$ $=.004]$. Pairwise comparison demonstrated no co-location to be associated with significantly 
greater speed variability than triple co-location $(p=0.006)$. Considerable variability was observed in the percentage of time spent above the speed limit. Almost all participants drove above the speed limit at some point (no co-location $=94.4 \%$, dual co-location $=$ $58.3 \%$, triple co-location $=86.1 \%)$. The mean percentage of time driving over the speed limit did not significantly differ between conditions (no co-location $=8.00 \mathrm{~min}(\mathrm{SD}=1.96)$, dual co-location $=4.12 \mathrm{~min}(\mathrm{SD}=1.63)$, triple co-location $=9.60 \mathrm{~min}(\mathrm{SD}=3.79))$. Speed variables are presented in Table 2.

Table 2: Mean vehicle speed metrics and standard error of the mean for each of the three sign conditions under standard driving $(100 \mathrm{~km} / \mathrm{h}$ free flow traffic)

\begin{tabular}{llllll}
\hline & \multicolumn{3}{c}{ Condition } & ANOVA result & $p$ value \\
\cline { 2 - 5 } & No co-location & Dual co-location & Triple co-location & & \\
\hline Mean Speed $(\mathrm{km} / \mathrm{h})$ & $92.10(0.99)$ & $91.46(0.87)$ & $91.54(1.13)$ & $\mathrm{F}(2,68)=.401$ & .671 \\
$\begin{array}{l}\text { Maximum speed } \\
\text { (km/h) }\end{array}$ & $99.04(0.88)$ & $96.94(0.86)$ & $95.80(1.03)$ & $\mathrm{F}(1.70,57.93)=$ & $.002^{*}$ \\
$\begin{array}{l}\text { SD of speed }(\mathrm{km} / \mathrm{h}) \\
\begin{array}{l}\text { \% of time over the } \\
\text { speed limit }\end{array}\end{array}$ & $3.74(0.27)$ & $3.01(0.21)$ & $2.68(0.21)$ & $\mathrm{F}(2,68)=6.073$ & $.004^{*}$ \\
\hline
\end{tabular}

Note: Mean results from 35 participants. ${ }^{*}$ denotes significant results

\subsubsection{Eye tracking}

A total of 108 drives were completed across the three conditions. In eight drives the eye tracking was successful for less than $85 \%$ of the time and these data were excluded. A further seven drives were excluded because of failure to identify when participants looked at the signs. This resulted in usable eye tracking data from 32 No co-location drives, 32 dual co-location drives and 28 triple co-location drives. 24 participants had usable eye tracking data from all three scenarios, nine participants had useable eye tracking from two scenarios, two participants had usable eye tracking from one scenario and one participant had no usable eye tracking data. 
The proportion of time participants spent looking at the road was significantly affected by the scenario $\left[F_{(2,54.47)}=21.938, \mathrm{p}<.001\right]$. A pairwise comparison identified that a significantly longer period of time was spent looking at the road under triple co-location compared to no co-location and dual co-location $(\mathrm{p}<0.001)$. The proportion of drive time participants spent looking at road signs did not differ between conditions. There was a significant effect of sign co-location on the maximum glance time at any one sign $\left[F_{(2,57.39)}=9.431, p<.001\right]$. Pairwise comparison identified that the maximum glance time at a single sign was significantly shorter in triple co-location than for either no co-location or dual co-location $(p=.001)$. The opportunity a driver has to look at signs is influenced by the duration of time spent on the section of road being analysed. The duration of driving time for participants with usable eye tracking data significantly differed between conditions $\left[F_{(2,56.53)}=1432.82, p<.001\right]$. Pairwise comparison identified the drive time for triple co-location to be significantly shorter than for either no co-location or dual co-location $(p<.001)$. The results are presented in Table 3. 
Table 3: Mean eye tracking metrics and standard error of the mean for each of the three sign conditions under standard driving $(100 \mathrm{~km} / \mathrm{h}$ free flow traffic)

\begin{tabular}{|c|c|c|c|c|c|}
\hline & \multicolumn{3}{|c|}{ Condition } & \multirow{2}{*}{$\begin{array}{l}\text { Linear Mixed Model } \\
\text { result }\end{array}$} & \multirow[t]{2}{*}{$p$ value } \\
\hline & No co-location & Dual co-location & Triple co-location & & \\
\hline $\begin{array}{l}\% \text { gaze time on the } \\
\text { road }\end{array}$ & $52.24(4.61)$ & $48.60(4.61)$ & $72.62(4.70)$ & $\begin{array}{l}F(2,54.47)=21.938 \\
\text { Intercept Beta }=52.24 \\
{[42.98 ; 61.45]} \\
\text { Dual co-location Beta } \\
=-3.64[-10.81 ; 3.53] \\
\text { Triple co-location Beta } \\
=20.39[12.70 ; 28.01]\end{array}$ & $<.001^{*}$ \\
\hline $\begin{array}{l}\% \text { gaze time on the } \\
\text { signs }\end{array}$ & $16.38(2.13)$ & $15.67(2.13)$ & $13.73(2.19)$ & $F(2,56.45)=1.087$ & .344 \\
\hline $\begin{array}{l}\text { Mean glance time } \\
\text { on } 1 \text { sign (sec) }\end{array}$ & $0.53(0.06)$ & $0.59(0.06)$ & $0.47(0.06)$ & $F(2,60.73)=1.437$ & .245 \\
\hline $\begin{array}{l}\text { Maximum glance } \\
\text { time on } 1 \text { sign (sec) }\end{array}$ & $2.12(0.22)$ & $2.17(0.22)$ & $1.30(0.23)$ & $\begin{array}{l}F(2,57.39)=9.431 \\
\text { Intercept Beta }=2.12 \\
{[1.68 ; 2.56]} \\
\text { Dual co-location Beta } \\
=0.51[-0.37 ; 0.47] \\
\text { Triple co-location Beta } \\
=-0.83[-1.27 ;-0.38]\end{array}$ & $<.001^{*}$ \\
\hline $\begin{array}{l}\text { Duration of zone } \\
\text { (sec) }\end{array}$ & $54.77(0.58)$ & $55.16(0.58)$ & $31.17(0.60)$ & $\begin{array}{l}F(2,56.53)=1432.82 \\
\text { Intercept Beta = 54.77 } \\
{[53.61 ; 55.93]} \\
\text { Dual co-location Beta } \\
=0.39[-0.55 ; 1.33] \\
\text { Triple co-location Beta } \\
=-23.59[-24.60 ;- \\
22.59]\end{array}$ & $<.001 *$ \\
\hline
\end{tabular}

\subsection{Response to the emergency event}

The emergency event successfully occurred in 85 out of the 108 drives. Successful events were defined as those where the sudden braking was initiated when the participant was within $100 \mathrm{~m}$ of the lead vehicle. In some situations an emergency event was not triggered as a result of limitations in the driving simulator software. In the majority of unsuccessful events, the participant's lane changing behaviour resulted in there being no vehicle in front of the participant to act as an emergency event vehicle, or because the participant's follow distance was too large to ensure that the lead vehicle was within $100 \mathrm{~m}$ at the onset of the braking event. The prevalence of successful braking events was not evenly distributed 
between conditions; therefore analysis using repeated measures ANOVA was not appropriate. Instead a linear mixed model approach was taken. The distribution of successful braking events was as follows:

- $\quad$ No co-location $=24 / 36$ braking events

- $\quad$ Dual co-location $=30 / 36$ braking events

- $\quad$ Triple co-location $=31 / 36$ braking events

18 participants experienced three braking events, 13 experienced two braking events and 5 experienced one braking event.

For the majority of emergency events the participants responded by slowing their speed, either through application of the brakes or release of the accelerator. The response of changing lanes was observed for 1 of the 24 events under no co-location, 6 of the 30 for Dual co-location, and 13 of the 31 for Triple co-location. Those participants who changed lanes were excluded from the minimum headway analysis.

Despite the precautions to ensure participants were not made aware if a collision occurred, out of the 85 braking events there were four noticeable collisions. Two of these collisions occurred during the participant's second drive. The remaining two occurred during the final drive. It is unlikely that prior exposure to a collision influenced the overall results because only two participants completed another drive after experiencing a collision.

Overall, there was no significant effect of sign co-location on reaction time to the emergency event or minimum headway. However, it was noted that there was a significant difference in the conditions at the onset of the event in terms of mean travel speed $\left[F_{(2,55.25)}\right.$ $=19.440, \mathrm{p}<.001]$ and headway $\left[F_{(2,55.10)}=3.447, \mathrm{p}=.039\right]$. Pairwise comparison identified 
travel speed under no-co-location to be significantly slower than under dual or triple colocation $(\mathrm{p}<.001)$, with no difference between dual and triple co-location. In relation to headway distance at the onset of the braking event, pairwise comparison identified the distance for no co-location to be significantly shorter compared to dual co-location $(p=.046)$, but not compared to triple co-location $(p=.124)$. Dual co-location and triple co-location were not significantly different from each other for headway at the onset of the event. Response time and minimum headway resulting from the emergency event are outlined in Table 4.

Table 4: Mean and standard error of the mean for emergency event response and onset conditions.

\begin{tabular}{|c|c|c|c|c|c|c|}
\hline & \multicolumn{3}{|c|}{ Condition } & \multirow{2}{*}{$\begin{array}{l}\text { Linear Mixed Model } \\
\text { result }\end{array}$} & \multirow[t]{2}{*}{$p$ value } \\
\hline & & $\begin{array}{l}\text { No co- } \\
\text { location }\end{array}$ & $\begin{array}{l}\text { Dual co- } \\
\text { location }\end{array}$ & $\begin{array}{l}\text { Triple co- } \\
\text { location }\end{array}$ & & \\
\hline \multirow{2}{*}{ 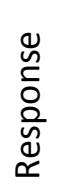 } & $\begin{array}{l}\text { Fastest RT } \\
\text { (seconds) }\end{array}$ & $1.13(0.13)$ & $1.40(0.13)$ & $1.33(0.12)$ & $F(2,48.93)=1.377$ & .262 \\
\hline & $\begin{array}{l}\text { Minimum } \\
\text { Headway (sec) }\end{array}$ & $1.71(0.18)$ & $1.58(0.17)$ & $1.32(0.20)$ & $F(2,39.47)=1.449$ & .247 \\
\hline \multirow[b]{2}{*}{ 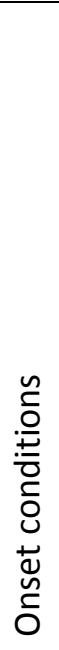 } & $\begin{array}{l}\text { Speed at the } \\
\text { onset of the } \\
\text { event }\end{array}$ & 63.14(1.32) & 72.39 (1.19) & 71.69 (1.17) & $\begin{array}{l}F(2,55.25)=19.440 \\
\text { Intercept Beta = 63.14 } \\
{[60.51 ; 65.77]} \\
\text { Dual co-location Beta }= \\
9.25[6.00 ; 12.50] \\
\text { Triple co-location Beta = } \\
8.55[5.33 ; 11.77]\end{array}$ & $<.001^{*}$ \\
\hline & $\begin{array}{l}\text { Headway at } \\
\text { the onset of } \\
\text { the event (sec) }\end{array}$ & 2. 32(0.17) & $2.83(0.16)$ & $2.74(0.16)$ & $\begin{array}{l}F(2,55.10)=3.447 \\
\text { Intercept Beta }=2.32 \\
{[1.98 ; 2.67]} \\
\text { Dual co-location Beta }= \\
0.51[0.10 ; 0.91] \\
\text { Triple co-location Beta }= \\
0.42[0.02 ; 0.82]\end{array}$ & $.039 *$ \\
\hline
\end{tabular}

Note: Fastest RT and all onset condition results are for 24 participants in no co-location, 30 in dual co-location and 31 in triple co-location. Results for the minim headway are for participants who did not change lane, 23 participants in no co-location, 24 in dual co-location and 18 in triple co-location.

* denotes significant results 


\subsubsection{Impacts of travel speed on response to emergency event}

As the emergency event always occurred in the same speed zone, the difference in travel speed was not expected and did not form part of the original analysis design. In an attempt to understand the potential impact travel speed may have had, exploratory analysis was undertaken to separately consider those events which occurred at $<70 \mathrm{~km} / \mathrm{h}$ and $\geq 70 \mathrm{~km} / \mathrm{h}$. Of the events occurring with an onset speed of $<70 \mathrm{~km} / \mathrm{h}, 22$ events occurred under no colocation, 13 under dual co-location and 13 under triple co-location.

Table 5 Mean and standard error of the mean for emergency event response when participant was traveling $<70 \mathrm{~km} / \mathrm{h}$ at the onset of the event.

\begin{tabular}{|c|c|c|c|c|c|c|}
\hline \multicolumn{2}{|c|}{ Response metric } & \multicolumn{3}{|c|}{ Condition } & Linear Mixed Model result & $p$ value \\
\hline Fastest RT & $<70 \mathrm{~km} / \mathrm{h}$ & $1.05(0.11)$ & $1.91(0.13)$ & $1.66(0.13)$ & $\begin{array}{l}F(2,39.05)=11.487 \\
\text { Intercept Beta }=1.05 \\
{[0.84 ; 1.26]} \\
\text { Dual co-location Beta }=0.86 \\
{[0.46 ; 1.26]} \\
\text { Triple co-location Beta }=0.61 \\
{[0.22 ; 1.01]}\end{array}$ & $<.001^{*}$ \\
\hline $\begin{array}{l}\text { Minimum } \\
\text { Headway } \\
\text { (sec) }\end{array}$ & $<70 \mathrm{~km} / \mathrm{h}$ & $1.62(0.19)$ & $2.12(0.29)$ & $1.42(0.31)$ & $F(2,30.18)=1.515$ & .236 \\
\hline
\end{tabular}

Note: Fastest reaction time was calculated for all participants traveling $<70 \mathrm{~km} / \mathrm{h}, 22$ participants in no co-location, 13 in dual co-location and 13 in triple co-location. Minimum headway values were calculated for participants who did not change lane, 21 participants in no co-location, 9 in dual co-location and 8 in triple co-location. * denotes significant results

Comparison was also made between response to the emergency event for dual co-location and triple co-location with faster approach speeds ( $\geq 70 \mathrm{~km} / \mathrm{h})$. This analysis included 17 events under dual co-location and 18 under triple co-location. The no co-location condition was excluded from this analysis because only two events occurred at the higher speed. The results are presented in Table 6. 
Table 6: Mean and standard error of the mean for emergency event response when participant was traveling $\geq 70 \mathrm{~km} / \mathrm{h}$ at the onset of the event.

\begin{tabular}{|c|c|c|c|c|c|}
\hline \multirow[t]{2}{*}{ Response metric } & & \multicolumn{2}{|c|}{ Condition } & \multirow{2}{*}{$\begin{array}{l}\text { Linear Mixed Model } \\
\text { result }\end{array}$} & \multirow[t]{2}{*}{$p$ value } \\
\hline & & Dual co-location & Triple co-location & & \\
\hline Fastest RT & $\geq 70 \mathrm{~km} / \mathrm{h}$ & $1.13(0.18)$ & $1.12(0.18)$ & $F(1,12.08)=.001$ & .975 \\
\hline $\begin{array}{l}\text { Minimum } \\
\text { Headway (sec) }\end{array}$ & $\geq 70 \mathrm{~km} / \mathrm{h}$ & $1.27(0.21)$ & $1.20(0.25)$ & $F(1,7.711)=.066$ & .804 \\
\hline $\begin{array}{l}\text { Note: Fastest r } \\
\text { co-location an } \\
\text { who did not ch }\end{array}$ & $\begin{array}{l}\text { eaction tin } \\
18 \text { in trip } \\
\text { lange lane. }\end{array}$ & $\begin{array}{l}\text { e was calculated } \\
\text { e co-location. M } \\
15 \text { in dual co-loc }\end{array}$ & $\begin{array}{l}\text { for all participants } \\
\text { imum values wer } \\
\text { tion and } 10 \text { in trip }\end{array}$ & $\begin{array}{l}\text { traveling } \geq 70 \mathrm{~km} / \mathrm{h} \text {, } \\
\text { e calculated for part } \\
\text { le co-location. }\end{array}$ & $\begin{array}{l}7 \text { in dual } \\
\text { pants }\end{array}$ \\
\hline
\end{tabular}

When only the slower speed emergency events are considered there is an effect of sign colocation on reaction time $\left[F_{(2,39.05)}=11.487, \mathrm{p}<.001\right]$. Pairwise comparison indicated that reaction time under no co-location was significantly faster than for dual $(p<.001)$ and triple $(p=.010)$ co-location. No significant difference was found between dual and triple colocation $(p=1.000)$. Although reaction time was slower under sign co-location, the minimum headway distance to the event vehicle did not vary significantly. There was no significant difference in emergency event responses for higher speed ( $\geq 70 \mathrm{~km} / \mathrm{h}$ ) braking events between dual and triple co-location. These analyses are exploratory and while there is an indication of effect, due to the smallness of the sample size and the repeated nature of analysis, the results should be read with caution.

\subsection{Decision making}

Almost all participants took the appropriate exit as per the instructions. No significant difference $\left[X^{2}(2, N=107)=0.88, p=0.664\right]$ in the frequency of participants correctly selecting the required destination was observed when compared between no co-location ( $\mathrm{n}$ $=28)$, dual co-location $(n=31)$ and triple co-location $(n=28)$. 


\subsection{Subjective workload}

Each item of the NASA-Task Load Index was considered independently. Only stressfulness exhibited a significant difference between conditions $\left[F_{(2,70)}=5.14, p=.008\right]$. Pairwise comparison identified triple co-location to be associated with significantly greater stress than no co-location $(p=.013)$. No significant difference was found between dual co-location and triple co-location $(p=.205)$. The results are outlined in Table 7.

Table 7: Mean NASA-Task Load Index scores for each of the three conditions and ANOVA results

\begin{tabular}{|c|c|c|c|c|c|}
\hline \multirow{2}{*}{ Workload dimension } & \multicolumn{3}{|c|}{ Condition } & \multirow{2}{*}{ ANOVA result } & \multirow{2}{*}{$p$ value } \\
\hline & No co-location & Dual co-location & Triple co-location & & \\
\hline Confusion & $1.89(0.21)$ & $2.03(0.17)$ & $2.31(0.25)$ & $F(2,70)=1.807$ & .172 \\
\hline Difficult & $2.31(0.19)$ & $2.44(0.19)$ & $2.58(0.29)$ & $\begin{array}{l}F(1.68,58.96)=.608 \\
\varepsilon=.84\end{array}$ & .521 \\
\hline Stressful & $2.53(0.20)$ & $2.81(0.24)$ & $3.31(0.30)$ & $F(2,70)=5.141$ & $.008^{*}$ \\
\hline Rushed & $1.75(0.16)$ & $1.92(0.21)$ & $2.44(0.59)$ & $\begin{array}{l}F(1.13,39.59)=1.107 \\
\varepsilon=.57\end{array}$ & .308 \\
\hline Successful & $4.81(0.40)$ & $5.39(0.32)$ & $4.81(0.38)$ & $F(2,70)=1.430$ & .246 \\
\hline Safe & $5.36(0.27)$ & $5.17(0.29)$ & $4.81(0.34)$ & $F(2,70)=2.155$ & .124 \\
\hline
\end{tabular}

Note: Mean results from 36 participants. ${ }^{*}$ denotes significant results

\section{Discussion}

The impact of co-locating signs on driving performance was investigated using a driving simulator. For the specific configuration of signs investigated, results suggests that colocating road signs does not negatively affect driving performance and has minimal impact on a driver's ability to respond appropriately to an emergency event. However, the "stressful" component of the workload scale was higher when signs were triple co-located.

\subsection{Response to an emergency event}

The first research question considered whether participants could safely respond to an emergency event while extracting information from co-located signs, compared to conventionally located signs. 
Overall, sign co-location did not influence participants' reaction times or minimum headway for the emergency event. This result supports that of a previous driving simulator investigation, where drivers were able to safely respond to an emergency braking situation while successfully detecting changes in direction sign information (Metz and Kruger 2014). In the current study, participants were more likely to change lanes in reaction to the emergency event in the triple co-location condition than in the no co-location condition. Considering that sudden lane changes have been associated with vehicle collisions (Jula, Kosmatopolous \& loannou, 2000), there is some potential for safety implications, and it would be beneficial for future research to examine this topic in more detail.

Interestingly, there was a significant difference in travel speed immediately before the emergency event, where it was observed that participants drove at slower speeds with no sign co-location. It is not clear why participants were driving slower with no sign co-location at the onset of the emergency event, particularly when they drove faster with no sign colocation under the standard driving condition. The higher travel speeds would have required a greater braking distance (Schweitzer, Apter et al 1995) to respond to the emergency event. However, the larger headway at the onset of the event would have allowed space to stop; this is reflected by no significant difference in minimum headway distance between conditions. Exploratory analysis of braking events which occurred when participants were traveling at slower speeds identified reaction times to be faster under no co-location than in the other sign conditions. Despite the faster reaction time the minimum headway to the vehicle in front was not significantly influenced. This difference in reaction time was not observed for higher travel speeds. This finding provides some suggestion that co-locating signs may have negative safety implications, with both dual and triple co-location being 
associated with a reaction time slower than the expected $1.25 \mathrm{sec}$ drivers reportedly take to respond to a lead car braking (Green 2000). However, despite a slowed reaction time there was no difference in minimum headway. This was likely influenced by a greater following distance at the onset of the event. A further consideration is that there was no difference in reaction time between triple co-located signs and dual co-located signs which are already commonplace on roadsides. This suggests that the introduction of triple co-located signs where dual co-located signs are already widespread is not likely to pose an additional safety hazard. Findings related to travel speed should be interpreted with caution because of small sample size and the repetition of analysis. The findings are presented here to indicate potential for influence, future research should employ rigorous methodology to consider the relationship between travel speed and sign co-location on emergency event response.

\subsection{Standard motorway driving}

The second research question considered whether co-locating signs impacts general motorway driving performance, in free flowing traffic, in terms of vehicle control and eye gaze.

Overall, participants spent a significantly greater proportion of time looking at the road during triple co-location than in the other two conditions. Despite this, there was no significant variation in the percentage of time spent looking at the signs between the three conditions. This implies that participants were looking at other periphery or in-vehicle areas during this scenario.

When considering road signs as an external distractor, arguably the most important safety consideration is the influence on off road glance duration. Glances away from the road of greater than two seconds have been identified as being safety critical and pose increased 
crash risk (Klauer et al., 2006). Under all three conditions, the mean glance duration at any sign for all participants was less than one second. The maximum glance duration was slightly over two seconds in the conventional no co-located condition and under dual co-location. It is therefore unlikely that the co-location of signs, in the manner presented in this study, would increase the number of off road safety critical glances in comparison to the impact of conventional not co-located signs. This result is in contrast to a previous driving simulator study where co-locating road signs increased single glance duration at signs (Larue et al., 2013). The major difference between the previous and current study is traffic volume. It is possible that participants adapted their glance pattern to match the driving situation, meaning that under the higher traffic volumes of the current study, participants were less willing to take their eyes away from the road for a prolonged period of time. This is also in line with the findings of a series of experiments, whereby drivers were observed to apply adaptable safe search strategies and thereby not be distracted by irrelevant advertising signs (Metz and Kruger 2014).

Overall, the current study found sign co-location to reduce maximum travel speed and speed variability. This is possibly a reflection of the combined influence of VMS with VSL. Previous work has demonstrated that using VMS independently located between VSL can improve speed restriction compliance (Lee \& Abdel-Aty 2008). In the current study, travel times on a VMS were co-located with VSL; this co-location may have had greater benefits for speed restriction compliance than when the signs were presented independently. It is important to note that while the maximum travel speeds in the current work significantly differed between conditions, the mean speed for all three scenarios was below the posted 
speed limit. This is reflective of general on-road Australian driver behaviour where mean free-flow traffic speed in a $100 \mathrm{~km} / \mathrm{h}$ zone is reported to be $93.8 \mathrm{~km} / \mathrm{h}$ (Giles 2004).

\subsection{Subjective workload}

The final research question investigated was: does co-locating signs increase subjective workload associated with driving?

Co-locating road signs had very little impact on the self-reported subjective workload experienced by participants. Of the six NASA-Task Load Index items, the only observed difference between conditions was for stressfulness, with triple co-location being rated statistically significantly more stressful than no co-location, but not statistically significantly different from dual co-location. It should be noted that triple co-locating signs is not common practice in Australia. Therefore, it is likely that this was the first time many participants had seen a triple co-located sign. It is possible that with increased exposure, and/or providing educational/awareness information about this sign arrangement, there may be a decrease in the high stress rating. However, although there is a statistically significant difference between the mean ratings of stress this might not be considered to be of practical significance. In comparison between no co-location and triple co-location the stress rating increased by 0.78 , with the stress rating under triple co-location itself $(3.31 / 7)$ not being particularly high. Furthermore, despite the higher stress, sign co-location did not appear to have an effect on whether the correct exit was taken or on response to the emergency event. The fact that drivers took the right exit and adapt their speed to posted speed limits suggests that they saw and understood the signs in each condition, regardless of co-location status. 


\subsection{Conclusion}

The findings of the current study are representative of the specific sign arrangement tested. In this study signs were arranged horizontally, it is not possible to infer outcomes to other sign co-location arrangements. Furthermore, the impact of additional distractors, such as advertising signage, which may be apparent on real roads is unknown. Eye tracking data was recorded as an indication of attention being paid to the signs, however, while this indicates that signs have been looked at it does not mean they have been consciously perceived. Therefore, it is not possible to know if participants comprehended the signs based on eye glances. In addition, it may be possible for drivers to extract relevant information without directing their gaze at the sign, as research has shown that attention can be directed to a location while foveal fixation occurs at another location (Martens, 2000). However, driving behaviour in terms of taking the correct exit suggests that sign information was correctly comprehended, therefore providing strong suggestion that the signs were comprehended.

Importantly, this simulator study did not identify any higher risks of triple co-located signs compared to the current scenarios of no co-location and dual co-located signs. However, further evidence needs to be obtained from on-road trials to confirm these findings. Colocation of road signs is a practical option for displaying more road signs without taking up more road space. This has positive financial cost implications, as using existing gantries to display multiple signs would reduce construction and maintenance costs. It may also have safety benefits, as co-locating signs has the potential to provide opportunity to situate signs where previously space restrictions prevented it. For example, co-location may facilitate the use of VSL which has previously been demonstrated to reduce crash risk (Lee et al 2006). Furthermore, each new sign post or gantry introduced to the road network may present a 
new potential hazard with which vehicles may collide if the roadside is not already separated from the travel lanes by a safety barrier. By co-locating signs a greater volume of information can be displayed per road side hazard introduced.

In summary, co-locating road signs does not appear to negatively affect driving performance and has minimal impact on ability to respond safely to an emergency event.

\section{Acknowledgements}

This paper is based on findings from an Austroads funded project NT1782 Ability to Absorb Information through Electronic and Static Signs which was undertaken by ARRB and CARRSQ. The authors are indebted to Sebastien Demmel, Andrew Haines and Luke Daly for their help with the development of the driving simulator scenarios. The authors would also like to acknowledge contribution from the project manager and reference group members including Kelvin Marrett, Mana Tavahodi, Anna Clancy, Meredyth-Ann Williams, Jeremy Burdan, David Jorgensen, Jon Douglas, Aftab Abro, Rifaat Shoukrallah, Dave Landmark, Maurice Burley, Joanne Chang and Steve Clark. 


\section{References}

Castro, C., \& Horberry, T. (Eds.). (2004). The human factors of transport signs. CRC press.

Chatterjee, K., Hounsell, N.B., Firmin, P.E., \& Bonsall, P.W. (2002). Driver response to variable message sign information in London. Transportation Research Part C: Emerging Technologies, 10(2), 149-169.

Chatterjee, K., \& Mcdonald, M. (2004). Effectiveness of using variable message signs to disseminate dynamic traffic information: Evidence from field trails in European cities. Transport Reviews, 24(5), 559-585.

Costa, M., Simone, A., Vignali, V., Lantieri, C., Bucchi, A., \& Dondi, G. (2014). Looking behavior for vertical road signs. Transportation Research Part F: Traffic Psychology and Behaviour, 23, 147-155.

Divekar, G., Pradhan, A. K., Pollatsek, A., \& Fisher, D. L. (2012). Effect of external distractions. Behaviour and vehicle control of novice and experienced drivers. Transportation Research Record: Journal of the Transportation Research Board, 2321(1), 15-22.

Dutta, A., Fisher, D.L., \& Noyce, D.A. (2004). Use of a driving simulator to evaluate and optimize factors affecting understandability of variable message signs. Traffic Psychology and Behavior, 7(4), 209-227. doi: 10.1016/j.trf.2004.09.001

Edquist, J. (2009). The effects of visual clutter on driving performance (Doctoral dissertation, Monash University Accident Research Centre).

Edquist, J., Horberry, T., Hoskings, S., \& Johnston, I. (2011). Effects of advertising billboards during simulated driving. Applied Ergonomics, 42(4), 619-626.

Fang, C., Chen, S., \& Fuh, C. (2003). Road-sign detection and tracking. IEEE Trans on Vehicular Technology, 52, 1329-1341,

Giles, M. J. (2004). Driver speed compliance in Western Australia: A multivariate analysis. Transportation Policy, 11(3), 227-235

Green, M. (2000). How Long Does It Take to Stop? Methodological Analysis of Driver Perception-Brake Times. Transportation Human Factors, 2(3), 195-216.

Haque, M. M., \& Washington, S. (2013). Effects of mobile phone distraction on drivers' reaction times. Journal of the Australasian College of Road Safety, 24(3), 20-29

Han, C., \& Cairney, P. (2015). Ability to absorb information through electronic and static signs. Austroads report (No. AP-R485-15). 
Han C, Cairney P, Filtness P, Larue G, Schramm A and Rakotonirainy A (2016). Drivers' ability to absorb information from co-located sigs along motorways. Transportation Research Board $95^{\text {th }}$ Annual Meeting proceedings, Washington DC, US.

Hart, S. G., \& Staveland, L. E. (1988). Development of NASA-TLX (Task Load Index): Results of empirical and theoretical research. Advances in psychology, 52, 139-183.

Jensen, M.S., Yao, R., Street, W.N., \& Simons, D.J., (2011). Change blindness and inattentional blindness. Cognitive Science, 2, 529-546.

Jula, H., Kosmatopoulos, E. B., \& loannou, P. A. (2000). Collision avoidance analysis for lane changing and merging. Vehicular Technology, IEEE Transactions on, 49(6), 22952308.

Kaber, D. B., Liang, Y., Zhang, Y., Rogers, M. L., \& Gangakhedkar, S. (2012). Driver performance effects of simultaneous visual and cognitive distraction and adaptation behavior. Transportation Research Part F: Traffic Psychology and Behaviour, 15(5), 491-501.

Klauer, S. G., Dingus, T. A., Neale, V. L., Sudweeks, J. D., \& Ramsey, D. J. (2006). The impact of driver inattention on near-crash/crash risk: An analysis using the 100-car naturalistic driving study data (No. HS-810 594).

Larue, G. S., Schramm, A. J., Smith, S. S., Lewis, I. M., \& Rakotonirainy, A. (2013). The impact of co-locating regulatory and directional signs on driver performance. In Proceedings of Transportation Research Board 92nd Annual Meeting: Transportation Research Board.

Lay, M. G. (2004). Design of traffic signs. In C. Castro \& T. Horberry (Eds.), The human factors of transport signs (pp. 25-48). Boca Raton, FL: CRC Press.

Lee, C., \& Abdel-Aty, M. (2008). Testing effects of warning messages and variable speed limits on driver behavior using driving simulator. Transportation Research Record: Journal of the Transportation Research Board, (2069), 55-64.

Lee, C., Hellinga, B., \& Saccomanno, F. (2006). Evaluation of variable speed limits to improve traffic safety. Transportation research part C: emerging technologies, 14(3), 213-228.

Ma, R., \& Kaber, D.B. (2005). Situation awareness and workload in driving while using adapative cruise control and a cell phone. International Journal of Industrial Ergonomics, 35(10), 939-953.

Martens, M.H. (2000). Assessing Road Sign Perception: A Methodological Review. Transportation Human Factors, 2(4), 347-357

Metz, B., \& Krüger, H.P. (2014). Do supplementary signs distract the driver? Transportation Research Part F: Traffic Psychology and Behaviour, 23, 1-14. 
Möri, M., \& Abedel-Halim, H.H. (1981). Road sign recognition and non-recognition. Accident Analysis \& Prevention, 13(2), 101-115.

Pylyshyn, Z. W., \& Storm R.W. (1988) Tracking multiple independent targets: Evidence for a parallel tracking mechanism. Spatial vision 3.3:179-197.

Schnell, T., Yekhshatyan, L., \& Kaiker, R. (2009). Effect of Luminance and Text Size on Information Acquisition Time from Traffic Signs. Transportation Research Record: Journal of the Transportation Research Board, 2122, 52-62.

Schweitzer, N., Apter, Y., Ben-David, G., Liebermann, D. G., \& Parush, A. (1995). A field study on braking responses during driving. Il. Minimum driver braking times. Ergonomics, 38(9), 1903-1910.

Siogkas, G.K., \& Dermatas, E.S. (2006). Detection tracking and classification of road signs in adverse conditions. In Electrotechnical Conference, 2006. MELECON 2006. IEEE Mediterranean (pp. 537-540).

Sisiopiku, V., Hester, D., Gan, A., Stavrinos, D., \& Sullivan, A. (2013). Digital $\quad$ roadside advertising and traffic safety. In ATINER's Conference Paper Series.

Transport and Main Roads (2013). Manual of Unifor Traffic Control Devices. Brisbane, Queensland Government.

Trick, L. M., \& Pylyshyn, Z. W. (1994). Why are small and large numbers enumerated differently? A limited-capacity preattentive stage in vision. Psychological review, 101(1), 80. 